\title{
Ecological Approach to the Second Language (L2) Teaching and Nepali English Teachers
}

\author{
Vishnu S Rai \\ Tribhuvan University, Nepal \\ raivishnu1@gmail.com
}

\section{Abstract}

Ecological approach to L2 teaching is based on the concept of language ecology. In this ever changing world nothing is static. After so many approaches, methods, views, and ideas, ecological approach has made its appearance on the ELT stage. The approach is new to many Nepali English teachers who equate it with teaching ecology through the English language. The present paper explores the origin of the approach, shows differences between ecological approach to L2 (English) from teaching ecology through English, presents situation of language ecology, and ELT in Nepal, and suggests what could be possibly the best ways to teach English in Nepal.

Keywords: language ecology, multilingualism, holistic approach, ELT

\section{Language Ecology}

Language ecology was originally defined in 1972 by the Norwegian Linguist Einar Haugen as 'the study of interactions between any given language and its environment' (Haugen, 2001). The definition echoes the German biologist Ernst Haeckl's (1866, as quoted in Kramsch and Steffenson, 2008) definition of ecology within the life sciences as 'die gesammte Wissenschaft von den Beziehungen des Organismus zur umgebenden Aussenwelt, wohin wir im weiteren Sinne alle Existenz-Bedingungen' rechnen können' (the total science of the organism's relations to the surrounding environment, to which we can count in a wider sense all "conditions of existence'" Today, language ecology has become a widespread approach within such fields as second language acquisition (SLA), bi- and multilingualism and diversity, death and revitalization (Crystal, 2000).

"A keyword in ecology, whether in life sciences, or in linguistics, is holism. A holistic approach to linguistics implies that language is not be studied as an isolated, self-contained system, but rather in its natural surrounding, i.e. in relation to the personal, situational, cultural, and societal factors that collectively shape the production and evolution of language, ontogentically as well as phylogentically. Linguistic holism leads to a number of methodological considerations, shared by the majority of ecolinguists." (Kramsch \& Steffensen, 2008) 
Language ecology or ecology of language advocates the dynamics of interaction and coexistence of all languages in a social context. 'A language ecology perspective follows the metaphor of an ecosystem with a balance ensuring survival of all species. In the case of languages, language ecology analyzes power dynamics and issues of equity and human rights as fundamental elements in the social use of languages. The goal is to ensure that the promotion of any one language, in the name of globalization, for example, does not make causalities of historically important local languages. Instead, these can become empowered as the result of increased social interactions with a larger world.' (Mora, 2013)

Ecological approach to language learning believes on the preservation and promotion of all the languages so called big and small, prestigious and non-prestigious of all language families that are used in a society. Everything in this universe has a place what is called ecology, and destruction or disappearance of one has negative effect on all the rest, and ultimately damages the ecological system. The same is true in language ecology, that is, death or disappearance of one language damages the language ecosystem. As we should maintain the ecological balance to keep our planet safe and beautiful so we should also try to maintain the language ecological balance by giving each language its proper place to keep our society safe and beautiful. This language ecology was highly disturbed in the last 200 years, with the consequent restriction and destruction of the habitats of the majority of the world's linguistic ecologies.

Language ecology is used in several fields including language teaching and learning, and scholars from different areas such as linguistics, applied linguistics, World Englishes, and literacy use this concept to develop frameworks for the protection and promotion of local and indigenous languages that are slowly disappearing. Language ecology supports 'bilinguialism and multilingalism, language policy (especially in developing countries), and language education, particularly vis-a-vis the role of English and today's world.'

\section{Ecological Approach to L2}

'Ecological approach' came as a reaction to the cognitive approach (Krashen, 1985) hypothesized that adult L2 learning involves formally studying grammatical structures and rules, and the learners can be under-users, over-users or optimal-users of the formal knowledge. He also thought that language is acquired in a predictable order (i.e. first noun and verbs, simple structures then progressively advance towards more complex tenses, conjugations and structures. The learner's advance happens with comprehensible input $(i+1)$ just above her lin- 
guistic competence. She learns by concentrating on meaning of the new sentences, not the forms. Lastly, the learner's emotional side is an important component of learning as right motivation is an anxiety free environment that encourages use of the language.

Unlike the Piagetian view of learning as a cognitive process in the brain, van Lier's ecological approach is influenced by Vygostky and Cole (1978)'s social constructivism where social interaction with more knowledgeable with others is believed to precede the cognitive development for a learner to advance to the Zone of Proximal Development (ZPD), and Bakhtin (1986)'s dialogic view of human utterances as interrelated responses with meanings inextricably linked to the culture. Under this approach, $\mathrm{L}_{2}$ learning environment is characterized as relations, possibility, opportunity, immediacy, and interaction that the learner faces... This approach is ecological in that the learner's attempt to look for interaction opportunities is understood as affordance (Gibson, 1977), how living organism perceive and adapt to the environment for survival.

Ecological approach which includes the idea of holistic approach that encompasses all those things that combining together create the environment of learning for the learner. The idea can be presented diagrammatically as shown below.

Keeping learner in the centre ecological approach to L2 teaching-learning advocates all those factors that help learner learn L2 better. To quote van Lier (2010) "...all elements within an ecosystem (such as a classroom) are interrelated. Research often isolates particular pieces of the puzzle in order to study them in de-

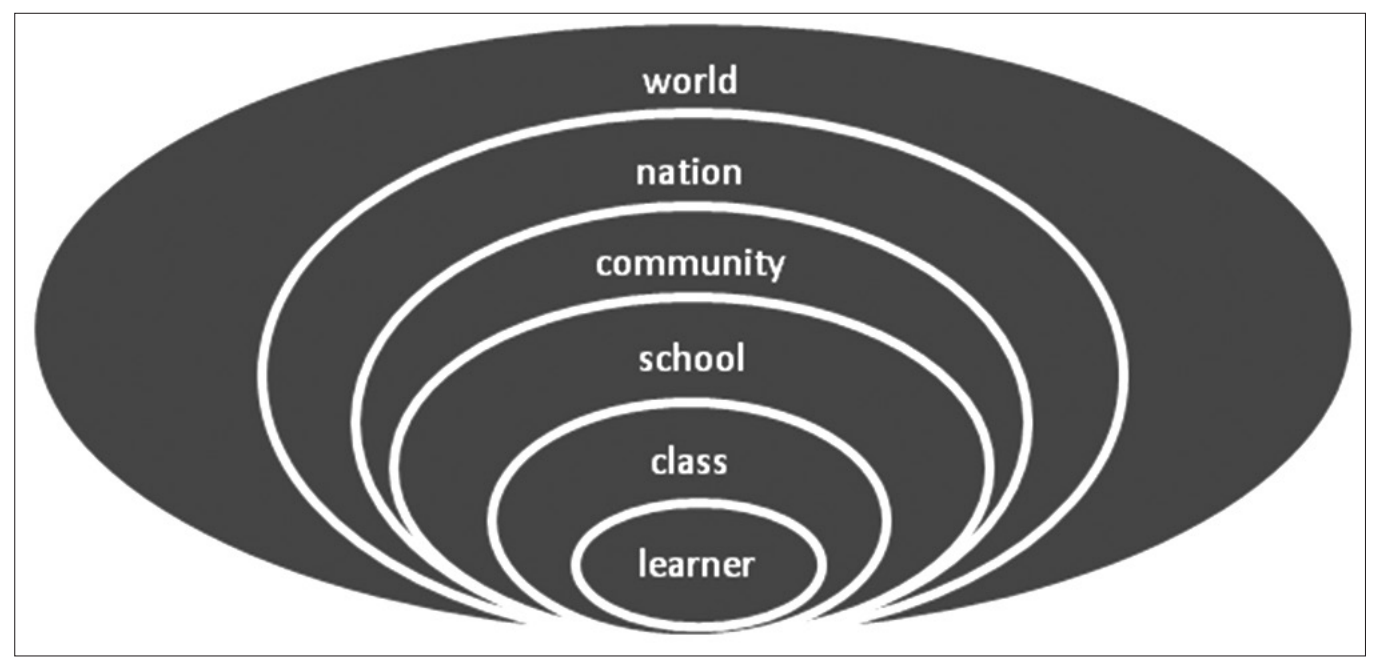


tail. However this useful may be, it obscures the dynamism of the actual teaching and learning work that goes on, and cannot show the emergent and contingent nature of that work." What does the ecosystem of a classroom consist of? Obviously all those elements that surround the learner and affect his L2 learning such as classmates, teacher, books, tests, etc., (school), mother tongue, culture, family, mother tongue- $L_{2}$ relationship, etc., (community), education policy and language policy of the state, etc., (nation) and so on.

As ecological approach to $L_{2}$ teaching-learning is based on the linguistic or language ecology, it supports and advocates of multilingual/ plurilingual approach of teaching, that is, $L_{2}$ (say English) is/should not be taught in isolation but with the native language of the learner. Use of mother tongue in an L2 classroom (say English) should not be considered as crime, and learner must not be punished if they use their mother tongue in an $L_{2}$ class. According to the spirit of the approach, teachers who know the learner's native language and culture are the best teachers. This means that a Nepali English teacher (non-native teacher) is a better teacher of a Nepali learner of English $\left(L_{2}\right)$, and not a native teacher (a teacher whose mother tongue is English). Besides all those elements that surrounds the learner such as local teaching learning materials, etc. help them learn L2 better.

\section{Linguistic Ecology of Nepal}

In order to understand the linguistic ecology of Nepal we have to look at the number of languages spoken in the country, their interrelationship and the language policy of the State. We will try to see this complex phenomenon in brief. First of all, Nepal is a multilingual country where over 100 languages are spoken. Except in a very few cases either in the remote mountain village, or in the remote Terai village, every Nepali is at least a bilingual. Many of the languages spoken by minority communities have no scripts and therefore no written tradition. Nepali is the official language: this is the language which is used by the government, used as medium of instruction in government school, and this is the language which is extensively used in media. Many languages spoken by the minority group are on the verge of extinction.

The constitution of Nepal guarantees the linguistic rights of every citizen: their right to promote their language and culture. It also declares that at least the primary education for the children should be given in their mother tongue, that is, the medium of instruction should be mother tongue in primary education. There is no any policy as such regarding English language teaching, however, English 
is the medium of instruction in private schools popularly known as 'boarding school' whether there are boarders or no boarders. And it is also true that many government schools have starting teaching English from Grade 1. Government has the policy that primary education must be given through mother tongue, but schools are using English (a foreign language) as the medium of instruction.

\section{ELT in Nepal: A Bird's Eye View}

English is still a foreign language in Nepal. It is true that it is popular and its popularity is growing every day. The private school with English as medium of instruction is mushrooming. Common Nepali people are led to believe that English is invariably essential for Nepali and for Nepal. Thousands of Nepali young men and women go to overseas countries as labours. They are led to believe that if you do not know English, you cannot get a job in overseas countries. But the fact is, that very few of them go to the countries of native speakers of English such as Australia, UK, and the US. Most of the Nepalese go to the Gulf countries, Malaysia, Korea and Japan. They have realized this myth of 'English is essential' and now they asking the language institutes and the government to teach them Arabic, Korean and Japanese, and consequently we see a lot of hoarding boards beside the road shouting, 'Learn Korean...' etc. There is no question to the fact that English is a must for higher education, but the number of Nepali going overseas for further education in comparison to do manual work, can be counted on fingers, and for such an insignificant number English as $L_{2}$ in Nepal should not be prioritized.

It is also a widespread common belief that if you teach English right from the beginning, say at the age of 4 or even earlier, kids will learn better. This is the reason that even some government schools has started teaching English from grade 1 . This belief is false because many studies conducted in different parts of the world have shown that $L_{2}$ (English) is learned better if the kids are exposed to it not at an early age but after 5 years of schooling. UNICEF has declared that the learners learn best if they are helped to learn through their first language, and if their competence in first language is good, it helps to $L_{2}$ better. Studies have shown that if kids are taught English at an early age, their English will be alright for a certain level, but their competency in English for higher level thinking will not be good: actually neither in $\mathrm{L}_{2}$ (English) nor in their own MT. 


\section{A Typical Nepali English Teacher}

Since beliefs, vies and attitude of a teacher towards teaching-learning have great impact in education we would briefly see a typical Nepali English teacher's beliefs and vies on ELT. Firstly, they believe that a native speaker teacher (English) is better than non-native teacher, and therefore they are in the vice-like grip of inferiority complex. They do not know, or do not want to know, that a non-native teacher (meaning they) are better because they know the learner, and his surrounding better than the native speaker teacher. It's true that he knows the language better, but he lacks the knowledge about the learner and his context. They also believe that local materials, such as textbooks are sub-standard or not good. They always go for those books written by native speakers, or Indian writers. The so called good schools do not use local text books but foreign books with strange topics and alien culture for Nepali children. Only second grade private schools use local textbooks.

Nepali English teachers are obsessed with good pronunciation or the 'RP' whatever that means. Their own pronunciation is typical Nepalese but they would like to have their students speaking English with RP (the BBC accent), and test their pronunciation not by listening to their pronunciation but in writing by asking them to look at the provided word/s and put the stress on a particular syllable, which is nothing but ridiculous and a complete waste of time. Our training organisations and trainers still have sessions on how to teach pronunciation.

One of the ridiculously dangerous beliefs is English is a better language than other languages, which leads them to have an inflated ego that they are English teachers, that they are superior than other subject teachers such as Social Studies teacher, or a Nepali teacher. They think that if someone does not know English, then he knows nothing. This leads them to use English and only English in their class, and helps them to justify their unforgivable action of punishing a child when $\mathrm{s} /$ he uses their mother tongue in an English class.

\section{Bitter Truth}

The truth, therefore, is that Nepali English teachers are far away from the ecological approach of $\mathrm{L} 2$ by trying to make their learners like native speakers by putting undue importance on pronunciation, by underrating the learner's mother tongue, by closing their eyes to local context. What they are doing as practising teachers of L2 (English) is not only un-ecological but wrong and unconstitutional. 


\section{Summing Up}

I would call 'summing up' of my article than 'conclusion', because there is no such thing as conclusion. So this summing up session forwards some suggestions.

In the context of Nepal, and in case of ELT, there should be more emphasis on practice than on theory -a shift from knowledge to action. Nepali English teachers have more than enough knowledge on how to teach better by engaging learners (using games, songs, tasks, and so on), how can the develop themselves (case studies, action research, reflective teaching, and so on), how to handle a large class, or how to help differently abled pupils or helping learners who speak different languages in the same class, and many other things. They know all. What they need is, actual practice in playing game with learners, doing action research, and conducting a multilingual class.

It seems necessary to educate not only parents but also the bureaucrats, about ecology of language and ecological approach to $L_{2}$ because the first is directly related to it whereas the second implement it. Parents need to be educated because they are ignorant, and it is not very difficult to wake up them from their sleep of ignorance, however, to educate bureaucrats is a herculean task because they do not want to be educated: they are not asleep but are pretending asleep, and to wake up a not-asleep person is very difficult.

There should be shift of focus from teaching is a skill to teaching is an art in pedagogy, and from listening and speaking to reading and writing in language skill teaching. It is sad but true that communicative method failed in the South East Asian countries not because teachers are not good or students are dull but because the learners have no opportunity at all to practice what they learned in their class once they come out of the class. It is also true that we learn English by reading and writing: no school in Nepal teach listening and speaking. It is, therefore, a must that more focus should be on reading and writing.

The Nepali English teachers and the Education Ministry, Nepal should realize that there is not just one English but Englishes in the present world. It is assumed, and the recent researches support the after 50 years or so native speakers of English might not be able to understand all the varieties which would be spoken in the world. They should realize that Nenglish or Nepali variety of English has made it appearance (Rai, 2008), which they will not be able to ignore in coming years. 
Lastly, there should not be testing. Testing for the purpose of saying pass or fail has done no good for anyone. Those who pass, particularly in higher grade are always in tension to maintain the position, and those who fail suffer a demoralized life. It is also a bitter truth that in an examination of 2 or 3 hours duration, there is no way that language proficiency can be tested or measured, and labelled as pass and fail. Testing should, therefore, be removed as it has been removed from school education in Finland and Singapore.

\section{References}

Bakhtin, M.M. (1986). Speech genres and other late essays. Trans. Vern W. McGee. Austin, Tx: University of Texas Press.

Crystal, D. (2000). Language death. Cambridge: Cambridge University Press.

Gibson, J.J. (1977). The theory of affordances. In R. Shaw \& J. Bransford (eds.). Perceiving, acting, and knowing: toward an ecological psychology (pp. 67-82). Hillsdale, NJ: Lawrence Erlbaum.

Haugen, C. (2001). Ecology of language, in A. Fill \& P. Mühlhäusler (Eds.). The ecolinguistic reader. language, ecology and environment continuum (pp. 5766).

Kramsch C., \& Steffensen, S.V. (2008). Ecological perspective on second language acquisition and socialization, https://www.researchgate.net/publication/226707454

Krashen, S. D. (1985). The input hypothesis: Issues and implications. New York: Longman.

Mora, R. A. (2013). The notions of second languages: Responding to today's linguistic ecology. The Journal for ESL Teachers and Learners, 2, 53-61

Skutnab-Kangas, T. (2000). Linguistic genocide in education -or World-Wide diversity and human rights. Mahwah, NJ: Lawrence, Erlbaum.

Van Lier, L. (2010). The ecology of language learning: Practice to theory, theory to practice. Social and behavioural Sciences 3, 2-6.

Vygotsky, Lev S. \& Cole, M. (1978). Mind and society: Development of higher psychological processes. Boston: Harvard University Press. 